\title{
Teachers' Psychological Quality of Ecological Education Wisdom
}

\author{
Hairong Zhu ${ }^{1, a}$ \\ ${ }^{1}$ School of Psychology and Education Science, Zaozhuang University, Zaozhuang, Shandong, \\ China
}

a54756783@qq.com

Keywords: Teachers, Psychology quality, Ecological education, Educational wisdom.

\begin{abstract}
Teachers' psychological quality plays an important role in cultivating adolescents to develop as healthy people of society and ecological person. The rules and theories of psychology can be widely involved in educational activities and play a unique educational value. The concept of psychology is conducive to bridging the gap between scientific doctrine and humanism, from opposition to fusion, and promote the formation of healthy personality of adolescents. In order to meet the needs of the development of modern education, teachers should optimize the cognition of educating people by using the rules of psychology, improve the ability of ecological education, develop the psychological quality and enhance the educational wisdom.

From the point of view of educational ecology, human, education and environment are interrelated to form an interactive and dynamically balanced ecosystem. Educators and the educated as the main body of education, are in mutual influence, mutual restraint, self-regulation of the movement to seek development. From the psychological point of view, the stage of compulsory education is an important period for young people to identify themselves, develop interpersonal relationships, develop good characters and learn to learn. Adolescents in the process of growth,will interact with the various factors in the system, and make a certain response. For a long time, they will accumulate and form some fixed reaction patterns, which will directly affect the formation and development of their personality. Therefore, teachers' psychological quality plays an important role in cultivating adolescents to develop as healthy people of society and ecological person. Teachers' psychological quality should include two aspects: on the one hand, teachers' psychological adjustment ability, on the other hand, the teachers' cognition and ability of using the rule of psychology.This article discusses from the second aspect that teachers' psychological quality is the foundation of educational wisdom.
\end{abstract}

\section{The Lack of Teachers' Psychological Quality}

As a case study of psychological research and practice of group counseling, Through the Chinese academic journal full text database (CNKI) to retrieve, Enter the keyword "group counseling", Sort by subject, and Choose the top 100. According to the statistics, we can find from the topic that college students as the object of study for the $50(50 \%)$, the middle school students as the research object for the $5(5 \%)$, children and adolescents as the research object for the $4(4 \%)$. According to the statistical results, we can not help but reflect: why is there so little practice and Research on group counseling in primary and secondary schools? And, by reviewing the literature, we found that the paper about class construction and team activity were more abundant. Therefore suggests that: in the stage of compulsory education, teachers focus more on class activities from the perspective of pedagogy, and lack of the necessary psychological theory and practice.The teacher's psychological literacy basically stay in the basic psychology in the normal education, and even did not learn educational psychology.In fact, it is far from being able to meet the needs of education and teaching.The perception that psychology is the mental health service is common in teachers.Teachers are less aware of the theory and technology of psychology, as well as the relationship between education and life.Their psychological quality should keep pace with the times, in order to meet the needs of the development of educational modernization. 


\section{The Demand of the Teachers' Psychological Quality}

Teachers have educational knowledge, educational means and educational beliefs, still not enough to achieve ecological education. Teachers' good psychological quality is the foundation of educational activities. Teachers and students are in a complex and diverse educational ecosystem. Teachers can play an important role in the cultivation of students' core quality and the promotion of physical and mental development.Teachers integrate individual development and group development of the psychological concept into the educational activities, to deepen the educational value of education activities,to enhance the effectiveness of education, to avoid educational activities in a mere formality, and even to distort value. Education activities should be based on students' life growth. Teachers need to know about a particular age students physiological needs, security needs, love and belonging needs, respect needs and self-actualization needs, activities will produce educational effects, lay a good foundation for the growth of his life, enable students to prepare for the future to paint a beautiful life. The process of teachers' self renewal and self transcendence is also the process of achieving real growth. Teachers and students share a common discourse, and in this atmosphere to express, experience and enhance the spiritual life.

\section{The Educational Value of Teachers' Psychological Quality}

The law of education is inherent in educational activities. Class life as a unique educational activities in the field of practice, its main function is to promote students' moral growth, social development, healthy development of personality and the development of public spirit. The law of education based on psychology will play its unique educational value.The concept of psychology is conducive to bridging the gap between scientific doctrine and humanism, from opposition to fusion, and promote the formation of healthy personality of adolescents.

In this paper, we discuss the educational value of human-centered theory, behaviorism theory, social learning theory, group dynamics theory and interpersonal communication theory, and discuss how teachers follow the psychological laws of human beings to carry out educational activities.

3.1 Human-centered Theory. Rogers' human nature is positive and optimistic, that people are rational, constructive, social, trustworthy, and cooperative. As a group leader, teacher's attitude is more important than technology.As a group, the class can provide the psychological atmosphere to promote the change of all the members of the class.Members will be able to develop towards the direction of self realization. To achieve this goal, as a group leader, teachers need to have three basic feed conditions: sincerity, unconditional positive regard and empathy. "Ecological" as the core of the "human-oriented" is the real "human-oriented", is the real respect for ecological life of education ${ }^{[1]}$. 3.2 Behaviorism Theory. Behaviorism holds that any action is caused by a stimulus, which is a response to a stimulus. The response pattern is the result of learning. Good behavior and bad behavior are acquired through acquired learning. Teachers can focus on the current behavior of students, make action plan,t hrough learning and training to eliminate the behavior of students which are not welcome, to shape the expected behavior habits. The scientific nature of behaviorism is never out of date, and teachers should pay attention to avoid the tendency of behaviorism to pay too much attention to scientific methods and technical means.

3.3 Social Learning Theory. Social learning theory holds that children's behavior is the product of interaction between individual and environment. Children usually acquire knowledge, skills and behavior by observing and imitating other people's behavior, especially in social life. Aggressive behavior and adaptive behavior are like this. In some class activities, teachers should create an environment for the students, and provide an example can be imitated, give full play to the value of words and deeds. Of course, teachers should avoid the tendency to exaggerate the role of the model and the environment ${ }^{[2]}$.

3.4 Group Dynamics Theory. Group dynamics is intended to explore the rules of group development, the inner dynamics of groups, groups and individuals, relationships with other groups, and the whole society ${ }^{[3]}$. Its theoretical basis is Lewin's field theory. The basic concept is living 
space, which includes people and environment. The environment is physical, psychological, and social. An individual is not a mechanical addition of isolated individual attributes, but rather a whole system in a certain living space. Tt emphasizes on dynamic relationship and interdependence, with dialectical implication. The democratic leadership style to create community atmosphere can improve the work efficiency. While the autocratic leadership style can guarantee the efficiency of the work, but the members lack the sense of trust and creativity. Group cohesion is expected to be achieved by teachers' educational activities. Therefore, teachers should choose appropriate leadership in educational activities in order to create an efficient and attractive group atmosphere.

3.5 Interpersonal Communication Theory. Interpersonal communication theory mainly includes interpersonal needs theory, social exchange theory, fair theory and symbolic interaction theory. All educational activities will be generated in the process of interpersonal communication. Whether educational activities can achieve their goals, the group communication is closely related.Teachers must understand how to build an effective group communication model, And use it properly. Interpersonal communication theory is helpful for teachers to establish good interpersonal relationships, avoid or reduce communication barriers. It also provides specific methods and skills for teachers to observe and guide the students to communicate with each other, and to grow in the coordination of interpersonal relationship.

\section{The Integration of Teachers' Psychological Quality}

At present, Chinese primary and secondary school teachers are sensible and lack of rationality. They are subjective and emotional when carrying out educational activities. The evaluation of the effectiveness of educational activities is subjective and one-sided, narrow and short. These phenomena are more common. Their evidence-based education consciousness is very weak. There is a distance between abstract theory and fresh practice, leading to the division of educational theory and practice ${ }^{[4]}$. Teachers should combine professional wisdom and relevant evidence to follow the best evidence for educational practice. The psychological point of view is through the conclusion of the experiment, with a high level of evidence. Teachers should constantly strengthen their own psychological quality and scientific literacy, improve the educational practice ability and the educational wisdom. Teachers should be highly sensitive and alert to sensibility and rationality, the educational world and the real world will be unified.

All educational activities have to return to the students "life world" and they are in the world of natural attitude". Educational life is no longer fragmented, but full of vitality of the organic life of the world, is the practicality of life consciousness of ecological understanding and construction. If teachers for understand students more ecologically, grasp their psychological characteristics and psychological law, combine the interaction of psychology and Pedagogy, eally adhere to the students, pay attention to life dialogue, this will inspire exciting, abundant education resources, so that education activities glow, full of growth, and truly become the driving force of the development of each student's life.

\section{Acknowledgement}

This research was financially supported by the key discipline of Zaozhuang University:pedagogy.

\section{References}

[1] W. B. Ju, Humanistic psychology, Zhejiang Education Press, pp. 456-470,2003.

[2] C. Q. Liu, Social learning theory of moral education evaluation, Journal of qilu, vol.2, pp. 70-73, 2000. 
[3] W. D. Yang, H. S. Ye, To shorten the distance between educational theory and practice: based on the perspective of evidence-based education, Journal of nanjing normal university (social science edition), vol. 1, pp. 101-105, 1990.

[4] M. Ben-Daya, M. Darwis, and K. Ertogral, The joint economic lot sizing problem: Review and extensions, Journal of education research and experiment, vol. 3, pp. 12-17, 2010. 